\title{
A Segregação Sexual na Interação de Crianças de 8 e 9 Anos
}

\author{
FabríciodeSouza ${ }^{12}$ \\ Maria Margarida Pereira Rodrigues \\ UniversidadeFederaldoEspíito Santo
}

\begin{abstract}
Resumo
A segregação sexual é observada na interação entre crianças em diferentes culturas e grupos sociais. O presente trabalho investigou, sob uma perspectiva etológica, o papel das variáveis situacionais na regulação da segregação sexual durante as interações lúdicas. Registrou-se o comportamento, em vídeo, de um grupo de crianças de 8 e 9 anos, participantes do movimento bandeirante de Colatina/ES, Brasil. O número de componentes oscilou entre 9 e 18. Frente a esta variação, a análise incidiu sobre os comportamentos expressos nos diferentes contextos. Os meninos apresentaram um padrão de comportamento mais agitado que o das meninas. Estas se mostraram mais calmas entre si e mais agitadas em dadas interações com eles. Vánias foram as aproximações entre meninos e meninas e as interações não-agonísticas entre ambos. As variáveis situacionais e os estilos de brincadeira mostraram-se importantes na análise das diferentes categorias comportamentais, bem como na determinação da segregação sexual.

Palavras-chave: Crianças; desenvolvimento; interação social em crianças; sexo-diferenças.
\end{abstract}

\section{Sexual Segregation in Interaction of 8-9 Years Old Children}

\begin{abstract}
Sexual segregation is a common phenomenon observed during the interaction between children in different cultures and social groups. The present work studied sexual segregation under an ethological view aiming to understand the role of situational variables over the regulation of that behavior during play interactions. A group of 8-9 years old children from the Scout movement of Colatina/ES, Brazil, had their behaviors registered in a video cassette. Due to the possible changes in the numbers of participants during data collecting period (among 9 and 18), the analysis focused on the expressed behaviors in different contexts. The results showed that boys had a more agitated behavior pattern than girls. Girls showed up calmer during the contact between themselves and more agitated in some interactions with boys. Despite the differences, many kinds of contexts in which a closer contact between boys and girls, such as maintenance of non-agonistic interactions between both, were observed. Situational variables are discussed in the analysis of different behavioral categories, showing the importance of play style in the determination of sexual segregation.

Keywords: Children; development; social interaction among children; sex-differences.
\end{abstract}

A partir do terceiro ano de vida, a criança é capaz de fazer distinções de gênero e a interação social lúdica, já nessa idade, pode refletir as diferenças sexuais percebidas (Benenson, Pamass \& Apostolenis, 1997; Stagnitti, Rodger \& Clarke, 1997). É justamente em meio a esse processo de interação, baseado em uma separação entre os diferentes sexos, que a criança desenvolve, dentre outras coisas, diferentes padrões de comportamento que irão persistir durante sua vida adulta.

Segundo Oliveira (1996), a construção da individualidade, como pertencente a uma determinada categonia de gênero, inicia-se ao nascimento da criança. Essa construção ocome a partir da observação das próprias ações e das de

\footnotetext{
${ }^{1}$ Endereço para correspondência: Rua Francisco Eugênio Mussielo, 440, bl 10, 402, 29060-290, Vitónia/ES. Fone: (27) 3224-0638 / 9276-8170. E-mail: fabrissouza@hotmail.com

${ }^{2} \mathrm{O}$ presente artigo é parte da Dissertação de Mestrado defendida no Programa de Pós-Graduação da UFES em Novembro de 2000.
}

seu meio social e da categorização dessas ações como masculinas ou femininas. Estabelecido o processo de categonização, as crianças tendem a perceber e a avaliaro comportamento de seu próprio grupo e o dos demais, exagerando tanto algumas diferenças quanto algumas similaridades entre os mesmos (ver Tajfel, 1982).

Assim, a preferência das crianças por outras de seu próprio sexo, segundo Powlishta (1995), é acompanhada de: “a) exagero das diferenças entre meninos e meninas e das similaridades entre indivíduos do mesmo sexo, b) uso dos estereótipos de gênero e c) crença de que alguém de seu próprio sexo seja mais heterogêneo ou variável que outros" (p. 782).

Segundo Maccoby (1988), a tendência à composição de grupos segregados sexualmente aparece entre 2 e 3 anos de idade e intensifica-se com o aumento da idade. São as meninasquem primeiramente manifestam essa postura, em tomo dos 2 anos, quando começam a se aproximar mais umas das outras. Já os meninos pemanecem mais "neutros" até, aproximadamente, os 3 anose, quando atingem o quinto 
ano de vida, manifestam uma preferência bem mais forte do que as meninas porparceiros do mesmo sexo.

A preferência por parceiros de mesmo sexo, segundo Maccoby e Jacklin (1987), estania relacionada, principalmente, a três fatores: os diferentes estilos que meninos e meninas têm para influenciaros colegas, a esquiva de contatos que podem ser interpretados, pelos colegas, como relacionamentos românticos e a capacidade que adquirem de classificar os diferentes gêneros e assumiro próprio.

Discutindo as estratégias que meninose meninasutilizam para influenciar seus companheiros, Maccoby (1988) mostra que, de $3^{1 / 2}$ anos a $5^{1 / 2}$ anos de idade, as meninas apresentam aumento do uso de "sugestões educadas". Já entre os meninos, o que se observa é o desenvolvimento de um padrão em que prevalecem as "exigências diretas". Decome então que osmeninos, nesse peńodo de suas vidas, tomam-se cada vez menos responsivos às sugestões provenientes das meninas. Estas, por sua vez, crescem aprimorando um estilo de influência múltipla que dá resultados com as demais pessoas, mas é, progressivamente, cada vez menos efetivo com os meninos (ver também Powlishta \& Maccoby, 1990).

Sendo o estilo desenvolvido pelas meninas desprovido do efeito esperado sobre os meninos, é possível que tal fato seja tido como uma das possíveis justificativas para a esquiva da interação entre ambos, dado que pode ser, para as meninas, aversiva a interação com alguém que não responde a seus requenimentos verbais. Assim, elas evitam o contato com os meninos e isso dificulta a formação de grupos com crianças de ambos os sexos (Maccoby, 1990).

Argumentos semelhantes são apresentados porGeary (1998), mostrando-nos que os grupos formados pelas crianças estão ligados aos seus interesses mútuos e às suas habilidades de influenciar o comportamento de companheiros. Isso sugere que a segregação sexual, ao menos em parte, resulta tanto de diferenças sexuais nos interesses pelos tipos de brincadeiras como pelos diferentes estilos de influenciaros demais.

Para alguns pesquisadores, as explicações da preferência porparceiros de mesmo sexo devem serbaseadas na análise de fenômenos sócio-culturais. Segundo F. Braza, P. Braza, Camerase Muñoz (1997), a segregação sexual entre as crianças constitui-se mais como reflexo de um fenômeno social do que a manifestação de gostos e de preferências individuais da criança (ver também Maccoby, 1988, 1990). Nesse sentido, Zamberlam (1979) afirma que uma possível explicação para a segregação pode ser identificada na dependência entre o comportamento da criança e os estereótipos culturais do meio com o qual ela interage e na maior atenção dada à observância de padrões comportamentais que se expressem consonantes com tais estereótipos.

Alexandere Hines (1994) argumentam que os diferentes estilos de brincadeira não podem ser completamente tomados como justificativa para a segregação sexual porque as crianças manifestam sua preferência por outras de mesmo sexo, mesmo quando envolvidas em brincadeiras semelhantes. É provável, segundo estes autores, que a segregação seja um fenômeno cognitivo-social evidenciado a partirde quando as crianças adquirem uma compreensão acerca dos diferentes gêneros e começam a avaliaras demais de seu própnio gênero (vertambém Maccoby, 1988). Desse modo, embora haja a possibilidade de que os diferentes estilos de brincadeira iniciem e até mesmo reforcem 0 favoritismo por parceiros de mesmo gênero, esse padrão de seleção dá-se primeiramente com base na identificação de seu próprio gênero.

Nenhuma teoria consegue contemplar, por si só, a total complexidade envolvida na explicação da segregação entre as crianças e, tampouco, o papel que o estilo de brincadeira e a identificação dos gêneros desempenham em favor dessa preferência. Uma completa compreensão do fenômeno em questão somente senia possível através de um modelo teónico que incorpore aspectos de diversas teorias (Alexander \& Hines, 1994).

De outro lado, adespeito do grande número de pesquisas sobre o desenvolvimento da preferência por companheiros de mesmo sexo, a maior parte dos estudos foi conduzida em ambiente escolar e focalizou muito mais os comportamentos responsáveis pela segregação que os comportamentos exibidos nasinterações meninas-meninos. Supomos que o estudo das interações meninas-meninos poderá contribuirpara a compreensão da segregação sexual, especialmente em condições que permitam a formação espontânea de grupos e sejam caractenzadas pela ludicidade.

Nessa perspectiva, esta pesquisa teve como objetivo identificar a ocomência de comportamentos indicativos de segregação sexual e as possíveis variáveis envolvidas na determinação de tais comportamentos a partir da investigação das interações sociais espontâneas de crianças de 8 e 9 anos.

\section{Método}

Os sujeitos escolhidos para participarem deste estudo são as crianças de 8 e 9 anos, participantes do Movimento Bandeirante Marista, de Colatina/ES.

As crianças participam do movimento pelo tempo que desejarem. Por isso, durante a coleta de dados, houve variação no número de crianças observadas em função de saídas e da admissão de novos membros. O total de 
crianças participantes deste estudo variou de 9 a 18 , sendo que 8 meninos e 5 meninas tiveram seus comportamentos mais freqüentemente registrados por terem participado do movimento porquase todo o peńodo de coleta de dados.

O ambiente deste estudo constituía-se de uma vastaárea contendo um galpão coberto, quatro quadras poliesportivas, uma pista de corrida, dois campos de futebol e dois playgrounds

A coleta de dados ocomeu no período de reuniões semanais do grupo que aconteceram aos sábados das 14 às 17 horas. 0 registro era iniciado quando ocomia interação entre pelo menos duas crianças.

Enquanto aguardavam o início da reunião, as crianças tinham à disposição algumas bolas de futebol e de voleibol, além de poderem brincarnos playgrounds Jogos de equipe figuravam entre as atividades mais freqüentes que os coordenadores preparavam para as reuniões. Competições entre as equipes de meninos e de meninas altemavam-se com os peńodos em que os coordenadores afastavam-se das crianças, permitindo a elas escolher o tipo de brincadeira ou atividade.

Utilizou-se a vídeo-gravação para o registro dos comportamentos das crianças, quando estas estiveram em grupos de no mínimo dois membros. As filmagens aconteceram de forma a proporcionar.

- a observação das interações quando a(s) criança(s) brinca(m) em grupos compostos por parceiros de mesmo sexo - samesex peer

Tabela 1

CategoniasComportamentaisLtilizadas
- a observação das interações quando a(s) criança(s) brinca(m) em grupos compostos tanto por parceiros de mesmo sexo quanto por aqueles de sexo diferente do dela - mixed sex peer

Foram totalizadas 24 horas de registros, ao longo de 8 meses, referentes às interações das crianças tanto em situações livres da interferência direta dos coordenadores como naquelas em que estes se faziam presentes.

Decidiu-se registrartambém as interações das crianças durante a presença dos coordenadores porque, segundo Maccoby e Jacklin (1987), quando os adultos mantêm um contexto estruturado no qual a segregação é favorecida, as crianças segregam-se mesmo que na presença deles.

\section{Resultados}

Selecionaram-se para análise as interações das crianças em situação livre sem a interferência dos adultos na constituição dos grupos enos tipos de brincadeiras adotados. A decisão de excluirda análise asinteraçõesocomidas durante as atividades coordenadas pelos adultos deveu-se à constatação de que os adultos favoreceram e, em alguns casos, deteminaram a formação de grupos unissexuais.

Estabeleceram-se, então, categorias comportamentais, algumas das quais elaboradas por F. Braza e colaboradores (1997). A Tabela 1 apresenta o conjunto de categorias utilizadas neste estudo para a quantificação das interações vídeo-gravadas.

Comportamentos Descrição

Abraçar*

Acompanhar*

Ameaçar

Aproximar*

Bincadeira turbulenta

Importunar

Insultar

Jogar objetos no outro

Pedir para brincar
Por os braços ao redor dos ombros do colega

Locomoção simultânea / Desempenhar, conjuntamente, a mesma atividade desenvolvida pelo colega.

Tentativa de amedrontar ou intimidar o colega, verbal ou fisicamente.

Mover-se em direção ao colega reduzindo a distância entre eles.

Bincadeira de luta: "empurrar, puxar, golpear, perseguir e lutar (...). Operacionalmente definida como um padrão de agressão que possui um forte componente de sociabilidade e é oposto ao ataque na tentativa de provocarferimentos"(DiPietro, 1981)

Incomodar, provocar aborrecimento e/ou transtorno ao colega através de falas ou de gestos.

Xingar, falar alto de maneira agressiva com o colega. Zombar.

Arremessar algum objeto na direção do colega em resposta a alguma importunação ou insulto.

Acenar ou pedir verbalmente para que o colega permita o engajamento em algum tipo de brincadeirajá iniciado.

\footnotetext{
*F. Braza e colaboradores (1997).
} 
Os dados coletados com o registro das interações em grupos constituídos por iniciativa das próprias crianças foram agrupados de acordo com a constituição desses grupos. Tais grupos, temporaniamente constituídos, foram classificados da seguinte maneira: Grupo MO (inclui dados de todos os grupos compostos somente por meninos), Grupo MA (inclui dados de todos os grupos constituídos apenas por meninas) e Grupo MI (todos os grupos formados por crianças de ambos os sexos). Calculou-se a freqüência dos comportamentos que as crianças exibiam em um determinado grupo. Obtidas as freqüências dos diferentes comportamentos, estas foram transformadas em percentagens. A decisão de utilizar apenas dados percentuais decorreu do fato de os totais de meninos e de meninas serem diferentes.

Quando um grupo reunido continha a presença de meninos e de meninas, e um dos meninos emitia um comportamento direcionado a outro, esse comportamento era classificado como pertencente ao grupo MO, visto que o comportamento, mesmo com a presença de meninas, foi emitido porum menino e direcionado a outro. Sendo o comportamento direcionado tanto a um menino quanto a uma menina, o mesmo foi classificado como pertencente ao grupo M.

A Figura 1 mostra os percentuais de comportamentos emitidos em interações agonísticas (importunar, ameaçar, insultar e jogar objetos no outro) e aqueles manifestados nas de aproximação e de manutenção de interações (aproximar-se, acompanhar, abraçare pedirpara brincar).

Comparando as interações ocorridas nos grupos MI com os demais grupos, pôde-se constatar que neste houve

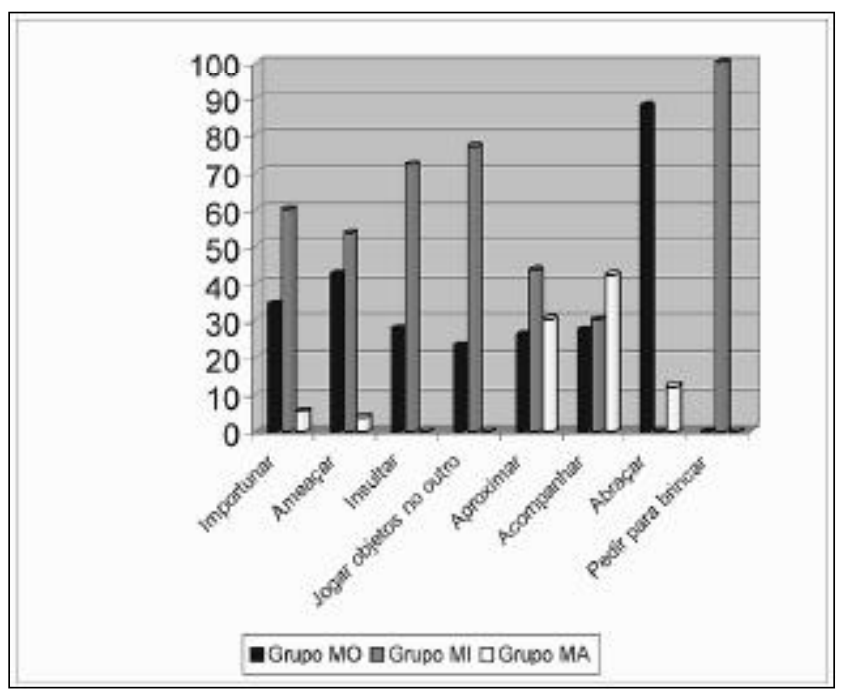

Figura 1. Interações agonísticas e de aproximação nos grupos formados somente pormeninos (MO), meninos e meninas (M) e somente por meninas (MA). percentagens mais altas de importunar (60\%), de ameaçar(53\%), de insultar (72,2\%) e de jogar objetos no outro (77\%). O grupo MO apresentou maior percentual de tais comportamentos quando comparado com o grupo MA, em que não ocorreram os comportamentos de jogar objetos no outro e insultar, tendo este grupo MA apresentado freqüências baixas para o importunare o ameaçar (5,6\% e 4\%, respectivamente).

Os comportamentos de abraçare de pedirpara brincar, em comparação com os de aproximar-se e os de acompanhar, apresentaram seus percentuais distribuídos imegulamente entre os três gnupos. A totalidade dos pedidos para brincar ocorreu no grupo MI, enquanto $87,8 \%$ dos abraços foram observados entre os meninos (grupo MO). Do total de aproximações, 43,7\% deram-se no grupo MI, $30,3 \%$ no MA e $26 \%$ no MO.

Os dados também mostram que as meninas foram as que mais apresentaram o comportamento de acompanhar umas às outras (42,4\%). Já os meninos obtiveram um percentual de $27,6 \%$ enquanto o registrado no grupo MI foi de $30 \%$.

As interações no grupo MI mostram-nos que os contatos entre meninos e meninas foram, freqüentemente, agonísticos. Comparando-se as percentagens de importunações, ameaças, insultose de jogarobjetosno outro, pode-se afirmar que as diferenças existentes entre os grupos MO e MA são indicativas de que os meninos interagem de maneira mais ativa e turbulenta. Em um primeiro momento, analisando as percentagens do grupo $\mathrm{MO}$, pode-se pensar que as meninas apresentam um padrão mais calmo de interação. Entretanto, o cálculo de percentagens e a verificação da tomada de iniciativa para tais comportamentos no grupo MI, como será mostrado adiante, evidenciam uma situação diferente.

Mesmo diante de interações agonísticas, deve-se assinalar a freqüência com que meninos e meninas aproximaram-se uns dos outros quando das interações no grupo MI. Somase a essa constatação o fato de que os pedidos para engajamento em bincadeiras somente ocomeram no intenior do grupo MI. Outro resultado interessante: os meninos abraçaram-se maisque as meninas.

Foram registrados 115 episódios de brincadeira turbulenta, que ocomeram tanto no grupo de meninos (MO) quanto entre estes e as meninas (M). Desse total, 77,4\% dos episódios aconteceram entre os meninos e 22,6\% envolveram meninos e meninas. Nos grupos compostos unicamente pormeninas não foram registrados quaisquer episódios de brincadeira turbulenta.

As brincadeiras turbulentas consistem em uma forma de interação através da qual as crianças empuram, puxam, dão socos, perseguem, lutam, agarram e apertam umas 
as outras. Como assinalado por DiPietro (1981), ainda que tais padrões motores, característicos desta brincadeira, algumas vezes permitam classificá-la como uma espécie de agressão, convém ressaltar que nela se inclui um componente fortemente ligado à sociabilidade. Isso permite opor a brincadeira turbulenta às brigas "de verdade" e a outras interações agonísticas, tais como as apresentadas na Figura 1, uma vez que nelas existe a real intenção de provocar ferimentos no parceiro ou o seu afastamento, intenção esta que se encontra ausente na brincadeira turbulenta (DiPietro, 1981). Por esse motivo, preferimos não incluirna figura 1 as percentagens relativas à brincadeira turbulenta.

No intuito de mostraro padrão de contatos que meninos e meninas exibiram quando interagiam no grupo MI, os dados apresentados na Figura 2 são especificamente restritos aos comportamentos emitidos nesse grupo. As iniciativas das interações eram tomadas tanto pelos meninos como pelasmeninas.

A maioria das importunações $(54,7 \%)$ partiu dos meninos e, provavelmente, em decorrência disso, as meninas iniciaram mais freqüentemente as ameaças (62,7\%), os insultos $(51,4 \%)$ e os arremessos de objetos dirigidos aos meninos (60\%).

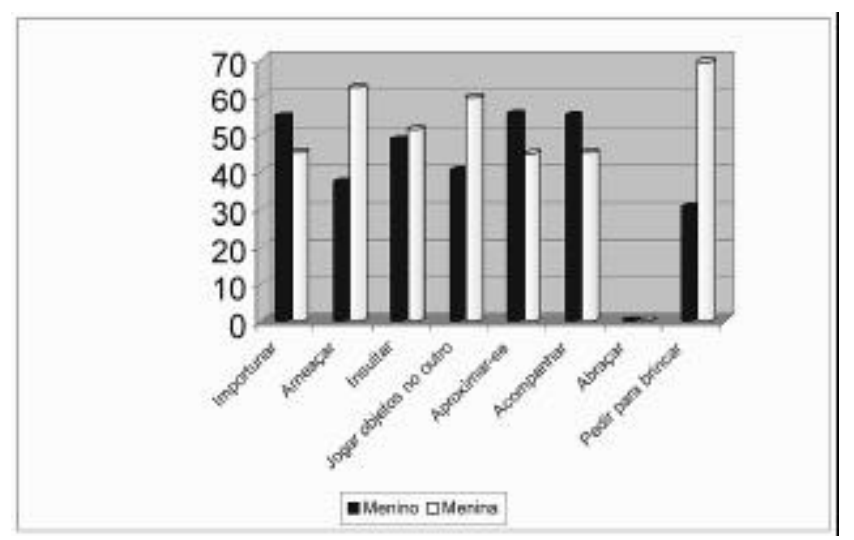

Figura 2. Interações agonísticas e de aproximação nos grupos mistos (M).

As aproximações mais freqüentes foram as dosmeninos para com as meninas (55,1\%). Eles também apresentaram percentagem maior de iniciativas para acompanhá-las (54,8\%) em alguma atividade que elas estivessem realizando. Entretanto, os pedidos para se insenir em uma brincadeira partiram, em sua maionia (69,5\%), das meninas. Nenhum abraço foi registrado no grupo MI.

Os resultados revelados pela Figura 2 confirmam que os meninos, como nos mostra a Figura 1, interagem de forma mais ativa e irrequieta. Entretanto, as meninas, na presença destes, passaram a manifestar as importunações
(45,3\%), os insultos e as ameaças que não apresentavam quando interagiam apenas entre si.

Envolvendo-se em muitas conversas, as meninas permaneceram por mais tempo paradas em um dado lugar. Esse padrão provavelmente favoreceu uma maior aproximação dos meninos em relação a elas (54,8\%).

Embora os meninos tenham se aproximado mais das meninas e acompanhado-as em algumas de suas atividades, deve-se notar que os pedidos para brincar, para inserir-se em algum tipo de brincadeira partiram mais das meninas visando à participação em brincadeiras como rebaterbola, cabo de guerra, futebol e para encenar "Os escravos de Jó". Dentre tais pedidos, os mais freqüentes foram para rebater bola e jogar futebol. Os meninos, por sua vez, quando pediram para brincar com as meninas, queniam rebater bola, encenar "Os escravos de Jó" e brincar de jogo da velha.

Supondo que as meninas parecem assumir padrões de interação mais "agitados" diante dos meninos, considerouse importante apresentar as tomadas de iniciativas quando da ocomência das brincadeiras turbulentas no grupo MI (verFigura 3).

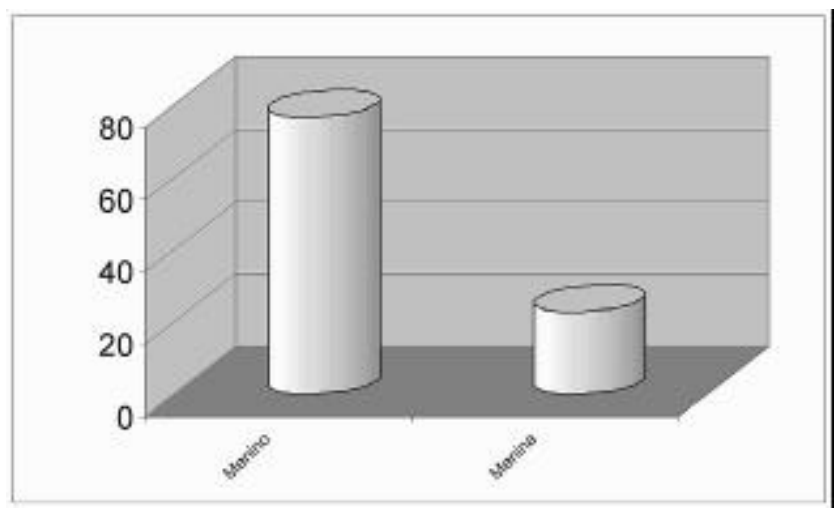

Figura 3. Brincadeira turbulenta no grupo MI.

Conforme Figura 3, as meninas iniciaram 23\% dos episódios de brincadeira turbulenta enquanto os demais $77 \%$ de iniciativas pertenceram aos meninos.

Os dados percentuais relativos à brincadeira turbulenta envolvendo meninos e meninas foram obtidos a partir de um total de 26 episódios deste tipo de interação. Desse total, 20 episódios foram iniciados pelos meninos e os 6 restantes pelas meninas.

Vale lembrar que esses 26 episódios de brincadeira turbulenta registrados no grupo MI representam 22,6\% do total registrado juntamente com os ocorridos apenas no grupo MO. 


\section{Discussão}

No grupo MI houve uma maior ocorrência de aproximações entre meninos e meninas do que entre meninos e meninos, no grupo MO, e de meninas e meninas, no grupo MA. No grupo MI, 55,1\% das iniciativas de aproximação partiram dos meninos, sendo interessante pensara importância que essas aproximações assumem na compreensão e no desenvolvimento dos rituais de acesso que virão a ter uma funcionalidade específica na vida adulta.

Segundo A. M. A. Carvalho eJ. E. C. Carvalho (1990), o contato social exige que um acesso ao espaço interpessoal do outro seja obtido pelos parceiros. Toma-se importante, então, conheceros processos envolvidos na iniciação dos contatos sociais entre as crianças devido à sua importância científica e social. Estes autores sugerem que, ao se utilizarem de estratégias de acesso a seus coetâneos, as crianças desenvolvem uma consciência acerca das funções dos rituais de acesso e isso seria uma caracteństica de grande valor para o desenvolvimento da competência social.

Algumas vezes os meninos se aproximaram das meninas no intuito de pedir algo a elas, de inserir-se em alguma atividade que estas estivessem desenvolvendo, como, por exemplo, brincarcom a bola, conversar, ou simplesmente para observaro que elas estavam fazendo no momento. Dependendo da atividade, eles mantinham a aproximação ou afastavam-se. Algumas dessas aproximações culminaram com algum tipo de importunação.

Os meninos mantiveram suas aproximações junto às meninas principalmente para conversar e participar de alguma atividade com bola ou outra atividade que envolvesse contatos físicos ou um padrão de interação mais agitado, como, por exemplo, encenar "os escravos de Jó". As meninas, por sua vez, aproximaram-se dos meninos no intuito de estabelecer uma conversa, para observar suas atividades ou para pedir algo a eles.

Poucos foram os comportamentos agonísticos registrados entre as meninas e insultos e arremessos de objetos não foram observados. As importunações e as ameaças apareceram com uma freqüência muito baixa quando comparadas com a ocorrência desses comportamentos entre os meninos.

Éno contato entre os sexos, no grupo M, que a situação se modifica. Os meninos continuam detendo a maior freqüência do comportamento de importunar, mas, para asmeninas, observou-se também um aumento. Em relação aos demais comportamentos agonísticos dispostos na Figura 2, as maiores percentagensforam registradas para as meninas. Os meninos apresentaram porcentagens não muito diferentes, com menorocomência do que as meninas.
Bussab (2000) comenta que o contato social, a interação e 0 vínculo encontram-se relacionados ao desenvolvimento psicológico do indivíduo e, sendo assim, agressão e apego são necessánios ao ajustamento do sujeito ao contexto sócio-afetivo de desenvolvimento, ou seja, "amor eódioseligam dediversasmaneiras" (p. 205). A autora ainda afima que a grande maionia de incidentes agressivos tem origem em algum tipo de problema ligado a relacionamentos estabelecidos pelos sujeitos.

Algumas dificuldades de interação e de ajustamento parecem estar associadas a uma ausência ou escassez de reações de defesa e de disputa (Bussab, 2000). Esse raciocínio dános pistasparapensarque exposição a situações agressivas em um contexto lúdico é funcional. Essa assertiva pode ser constatada na observação da brincadeira turbulenta, que parece seressencial ao desenvolvimento (Bussab, 2000).

Boulton (1996) discute que é possível, sob o ponto de vista evolucionário, imaginar que a brincadeira turbulenta proporcione muitos benefícios às crianças porque ocome a despeito de demandarum alto consumo de energia e risco de ferimentos. Um dos grandes benefícios, segundo o autor, estaria ligado à aquisição de habilidades para lidar com situações que podem colocar em risco a integridade física da criança.

Ao estudar as relações entre as brincadeiras turbulentas e as brigas reais entre as crianças, Smith (1997) apresenta quatro benefícios principais que, dentre outros, geralmente são atribuídos a este tipo particular de interação, que é o próprio "brincardebrigar" (Castro \& Carvalho, 1981). São eles: a) reforçar os laços e a coesão social, b) permitira prática de certas habilidades, tais como tomarparte nas resoluções de problemas e oportunizar a codificação e a decodificação de signos sociais, c) possibilitar o desenvolvimento de habilidades para lutar com e/ ou perseguiralgo (vertambém Boulton, 1996) e d) estabelecer ou manter as relações de dominância, fornecendo informações relevantes para tais relações durante os encontros entre as crianças (vertambém Boulton, 1996).

A proximidade e o contato físico, caracteństicos da brincadeiraturbulenta, pemitem-nos algumas considerações acerca das expectativas que meninose meninas apresentam frente às suas relações de amizade.

Ray e Cohen (1996) mostram-nos que, para os meninos, um dos fatores tidos como importantes ao se estabelecer uma relação de amizade é justamente a proximidade física. E, no grupo estudado no presente trabalho, $87 \%$ dos abraços envolveram meninos e nenhum abraço entre meninose meninas foi observado.

Não foi caracterizada uma situação específica que pudesse estar ligada à ocorrência dos abraços entre as meninas. Quando elas se abraçavam, o gesto de pôros 
braços ao redor dos ombros da colega acontecia em meio a conversas. Em algumas das vezes parecia que tal gesto era apenas uma extensão de seu comportamento verbal.

Com os meninos não foi assim. Quando estes se abraçavam era perceptível que tal gesto caracterizava situações bem específicas. A comemoração de algum feito que porventura eles tivessem conseguido, como fazer gols durante o jogo de futebol. Outras situações em que foram observados abraços entre os meninos foram: tentativa de convencer o colega de algo, chamá-lo para algum tipo de brincadeira ou para uma conversa. Por fim, a última situação foi a de resolução de conflitos.

Segundo Bussab (2000), existem certos comportamentosque são ritualizadose que têm porobjetivo atenuar a tensão de determinados encontros, promovendo um estreitamento do vínculo e uma diminuição do medo e da agressividade. Dentre esses comportamentos estão o aperto de mão e os tapinhas nas costas. $\mathrm{O}$ abraço também pode serincluído como tal.

Todas as interações envolvendo chamados ou pedidos para brincar foram seguidas de atividades lúdicas que não traziam em si a marca de uma tipificação sexual específica. Rebaterbola, encenar “Os escravos de Jó”, brincar de jogo da velha e jogarfutebol foram, com exceção deste último, atividades nas quais as crianças se envolveram sem demonstrar preocupação com sua adequação a meninos ou a meninas.

Referente à manutenção da segregação nos contextos organizados pelos adultos, observou-se o que nos afimmaram Maccoby e Jacklin (1987). Vánas foram as situações em que os coordenadores mantiveram uma estrutura que favoreceu a segregação porincentivarem a disputa entre os sexos, por reforçarem as diferenças entre ambos e por organizarem o grupo de modo que suas equipes fossem compostas exclusivamente pormeninos ou pormeninas. Em outras palavras, constatou-se que as crianças alvo desta pesquisa, mesmo diante dos adultos, exibiram padrões de comportamentos relacionadosà segregação sexual.

Nas condições do presente estudo, é possível assinalar que os principais determinantes da segregação sexual constituíram-se nos diferentes padrões de interação que as crianças demonstraram em suas atividades lúdicas.

De maneira geral, meninos e meninas mantiveram-se afastados uns dos outros porque elas mostraram-se mais calmas e envolvidas em conversas enquanto eles exibiram um padrão maisirrequieto eturbulento. Obviamente, esses padrões de interação, como pôde ser observado nos resultados obtidos, não se constituíram em exclusividade de nenhum dos sexos. Justamente por isso, em várias situações, as crianças interagiram de forma a permitir a proximidade dos colegas de sexo oposto.
Em algumas ocasiões, as meninas engajaram-se em brincadeiras turbulentas, e os meninos mantiveram diálogo com elas, inclusive porum tempo maior do que o fizeram entre si. A constatação desse tipo de comportamento mostranos a propriedade de novas pesquisas para a composição de mais dados referentesà importância do comportamento verbal e das brincadeiras turbulentas como determinantes da separação entre crianças de diferentes sexos.

No contexto em que se realizou este estudo, pôde-se observarque o ClubedoBolinha eoda Luluzinha interagiram em dadas ocasiões. A despeito das diferenças de interesses, motivações e níveis de atividade de meninas e de meninos, as interações inter-sexuais persistiram. Isto mostra que, embora diferentes padrões de interação se constituam em determinantesimportantes, não deve serdesconsiderado o pressuposto que considera a multiplicidade de determinantes na regulação dos comportamentos de segregação (Alexander \& Hines, 1994; Ge \& cols., 1996; Maccoby, 1988; Rutter, 1997).

Foi importante constatar como a segregação entre as crianças manteve-se constantemente ligada tanto ao contexto de interação das crianças entre si quanto ao de interação com os adultos. Tal constatação permite-nos ressaltar a pertinência do desenvolvimento de pesquisas com a finalidade de fundamentar novas hipóteses sobre a relevância do papel dos adultos na manutenção da segregação.

Embora o objetivo do presente trabalho não tenha sido investigarespecificamente os aspectos cognitivos, nem tampouco os biológicos, envolvidos na determinação da segregação sexual, pode-se afimar que os dados coletados com a pesquisa aqui descrita apontam para a importância que diferentes estilos de brincadeiras apresentados pelas crianças assumiram como variáveis situacionais na caracterização da segregação.

Talvez o emprego de uma metodologia que tenha primado pela observação direta do comportamento, caractenzando a pesquisa etológica, tenha favorecido a apreensão dosdados coletados de forma que este pudesse ser um resultado esperado. Entretanto, deve-se considerar que mesmo com o emprego de um instrumento que pudesse nos oferecer melhores condições para a avaliação dos aspectos cognitivos, foi muito marcante o fato de que a interação entre meninos e meninas se deu de maneira intensa e envolvendo padrões comportamentais aceitos pelas crianças dos dois gêneros em diferentes contextos.

\section{Referências}

Alexander, G. M. \& Hines, M. (1994). Gender labels and play styles: Their relative contribution to children's selection of playmates. Child Development, 65(3), 869-879. 
Benenson, J. F., Parnass, J. \& Apostoleris, N. H. (1997). Age and sex differences in dyadic and group interaction. Developmental Psychology, 33(3), 538-543.

Boulton, M. J. (1996). A comparison of 8- and 11-year-old girls' and boys' participation in specific types of rough-and-tumble play and aggressive fighting: Implications for functional hypotheses. Aggressive Behavior, 22, 271-287.

Braza, F., Braza, P., Cameras, M. R. \& Muñoz, J. M. (1997). Development of sex differences in preschool children: Social behavior during an academic year. Psychological Reports, 80, 179-188.

Bussab, V. S. R. (2000). Agressividade: A perspectiva etológica. Em R. R. Kerbauy (Org.), Sobrecomportamentoecognição: Conceitos, pesquisa eaplicação, a ênfasenoensinar, na emoçãoenoquestionamento clínico (pp. 201-209). Santo André, SP: Set.

Carvalho, A. M. A. \& Carvalho, J. E. C. (1990). Estratégias de aproximação social em crianças de dois a seis anos. Psicologia, 1(2), 117-126.

Castro, M. F. \& Carvalho, A. M. A. (1981). Incidentes agressivos na préescola. Psicologia, 7(2), 51-83.

DiPietro, J. A. (1981). Rough and tumble play: A function of gender. DevelopmentalPsychology, 7(1), 50-58.

Ge, X., Cadoret, R. J., Conger, R. D., Neiderhiser, J. N., Yates, W., Truoghton, E. \& Stewart, M. A. (1996). The developmental interface between nature and nurture: A mutual influence model of child antisocial behaviorand parents behavior. Developmental Psychology, 32(4), 574-589.

Geary, D. (1998). Male, Female: Theevolution of human sex differences. Washington DC: APA.

Maccoby, E. E. (1988). Gender as a social category. Developmental Psychology, 24(6), 755-765.

Maccoby, E. E. (1990). Gender and relationships. American Psychologist, 45(4), 513-520.

Maccoby, E. E. \& Jacklin, C. N. (1987). Gender segregation in childhood. Advancesin Child Developmentand Behavior, 20, 239-287.

Oliveira, Z. M. R. (1996). Interações infantis em creche e a construção das representações sociais de gênero. Em M. I. Pedrosa (Org.), Investigação da criança em interação social (pp. 69-82). Coletâneas da ANPEPP, 1(4).
Powlishta, K. K. (1995). Intergroup processes in childhood: Social categonization and sex role development. Developmental Psychology, 31(5),781788.

Powlishta, K. K. \& Maccoby, E. E. (1990). Resource utilization in mixedsex dyads: The influence of adult presence and task type. Sex Roles, 23(5/6), 223-240.

Ray, G. E. \& Cohen, R. (1996). Children's friendships: Expectations for prototypical versus actual best friends. Child Study Journal, 26(3), 209227.

Rutter, M. L (1997). Nature-nurture integration: The example of antisocial behavior. American Psychologist, 52(4), 390-398.

Smith, P. K. (1997). Play fighting and real fighting: Perspectives on their relationships. Em A. Schimidtt, K. Atzwanger, K. Grammer \& K. Schäfer (Orgs.), New Aspects of Human Ethology (pp. 47-64). New York: Plenum Press.

Stagnitti, K., Rodger, S. \& Clarke, J. (1997). Determining gender-neutral toys for assessment of preschool children's imaginative play. Australian Occupational Therapy Joumal, 44,119-131.

Tajel, H. (1982). Gruposhumanosecategoriassociais: EstudosdePsicologia Social (Vol.1). Lisboa: Livros Horizonte.

Zamberlam, M. A. T. (1979). Critériosdeadoção depapéissexuaisem situação de brinquedo. Dissertação de Mestrado não-publicada, Instituto de Psicologia, Universidade de São Paulo. São Paulo, SP.

\section{Sobre os autores}

Fabrício de Souza é Mestre em Psicologia pelo Programa de Pós-Graduação em Psicologia da Universidade Federal do Espínito Santo.

Maria Margarida Pereira Rodrigues é Doutora em Psicologia pela Universidade de São Paulo, Professora do Programa de Pós-Graduação em Psicologia da Universidade Federal do Espíito Santo. 